\title{
Changes in status of soil salinity in North Crimea since 2013, as detected by Landsat 8 OLI data
}

\author{
Igor Savin ${ }^{1,2 *}$ Elena Prudnikova ${ }^{1,3}$ \\ ${ }^{1}$ Peoples Friendship University of Russia (RUDN University), Faculty of Ecology, 6 Miklukho- \\ Maklaya Street, Moscow, 117198, Russian Federation \\ ${ }^{2}$ Belgorod State University, Federal-regional centre for aerospace and ground monitoring of objects \\ and natural resources, 308015 Belgorod, Russia \\ ${ }^{3}$ V.V. Dokuchaev Soil Science Institute, 119017 Moscow, Russia
}

\begin{abstract}
The purpose of this article is to analyze the changes in salinity of arable soils in the north of Crimea peninsula from 2013 to 2019 using Landsat 8 OLI satellite data in order to obtain additional and objective information about the modern state of soil secondary salinization processes. Comparison of the satellite data of 2013 and 2019 showed that in the area of the North-Crimean Canal there is both a slight expansion of the areas of saline soils and their reduction. The expansion of areas is observed mainly in the coastal zones of lakes and estuaries, and the reduction of areas in the fields, irrigation of which in the analyzed period did not stop. Both expansion and reduction of areas with saline soils did not exceed $10 \%$ of the study area. There is no evidence that the expansion of areas of saline soils during the analyzed period was due to the cessation of water supply to the North-Crimean canal.
\end{abstract}

\section{Introduction}

Salinity is one of the most significant properties of soils that limit their use in agriculture. According to FAO, soil salinity currently accounts for about $18-43 \%$ of the world's food shortages [1]. Saline soils occupy about 1 billion hectares of agricultural land worldwide [2].

The presence of saline soils in the soil cover is due to both natural causes and anthropogenic activities. As a rule, saline soils are confined to sediments containing soluble salts (ancient marine sediments of various ages). The manifestation of soil salinization is also caused by climatic conditions. With large amounts of precipitation, soluble salts, as a rule, are quickly washed out of the root layer of soil and have no effect on plant growth. Saline soils can also be caused by the high level of saline groundwater [1].

In addition to natural factors, the appearance of saline soils in the soil cover can also be caused by anthropogenic influence. In most cases, it is associated with the processes of

\footnotetext{
* Corresponding author: savin iyu@esoil.ru
} 
secondary salinization of soils under irrigation. Secondary salinization of soils is currently one of the most widespread types of soil degradation in the world $[3,4]$.

Natural processes of soil salinization are slow and most often associated with multi-year fluctuations in climate. Secondary anthropogenic salinization is a very rapid process, which can manifest itself widely in a few years [4]. At the turn of the 1990s, the area of secondary saline soils in arable land in Russia was about $1.5 \%$ [5]. Therefore, an important scientific direction is the development of methods for operative and accurate monitoring of the processes of secondary soil salinization.

Traditional monitoring methods based on field surveys with soil sampling and laboratory analysis are very time consuming and expensive [6]. In recent decades, methods based on the use of satellite data have been developed [7]. They are increasingly being introduced into the practice of monitoring the salinity of arable soils [2].

In 2014, after the Republic of Crimea became part of Russia, Ukraine stopped supplying water to the North Crimean Canal, which was the main source of irrigation for agriculture in the northern part of the peninsula. As a result, irrigation of many plots has ceased due to the lack of irrigation water. According to some reports, as a result of this, the processes of secondary salinization of soils in the area of the influence of the canal intensified, but there is confirmation of this only in some points [8]. The purpose of this article is to analyze the changes in salinity of arable soils of the region by satellite data in order to obtain additional and objective information about the modern state of secondary salinization processes.

\section{Object and Methods}

The research was conducted for the territory of the Perekop Isthmus and the North Crimean Channel area (Fig.1). This territory is characterized by flat relief, arid climate, semi-desert and dry-steppe natural vegetation, and the prevalence of soil complexes with participation of chestnut saline and saline soils in varying degrees, solonchaks and solonetzs [9].

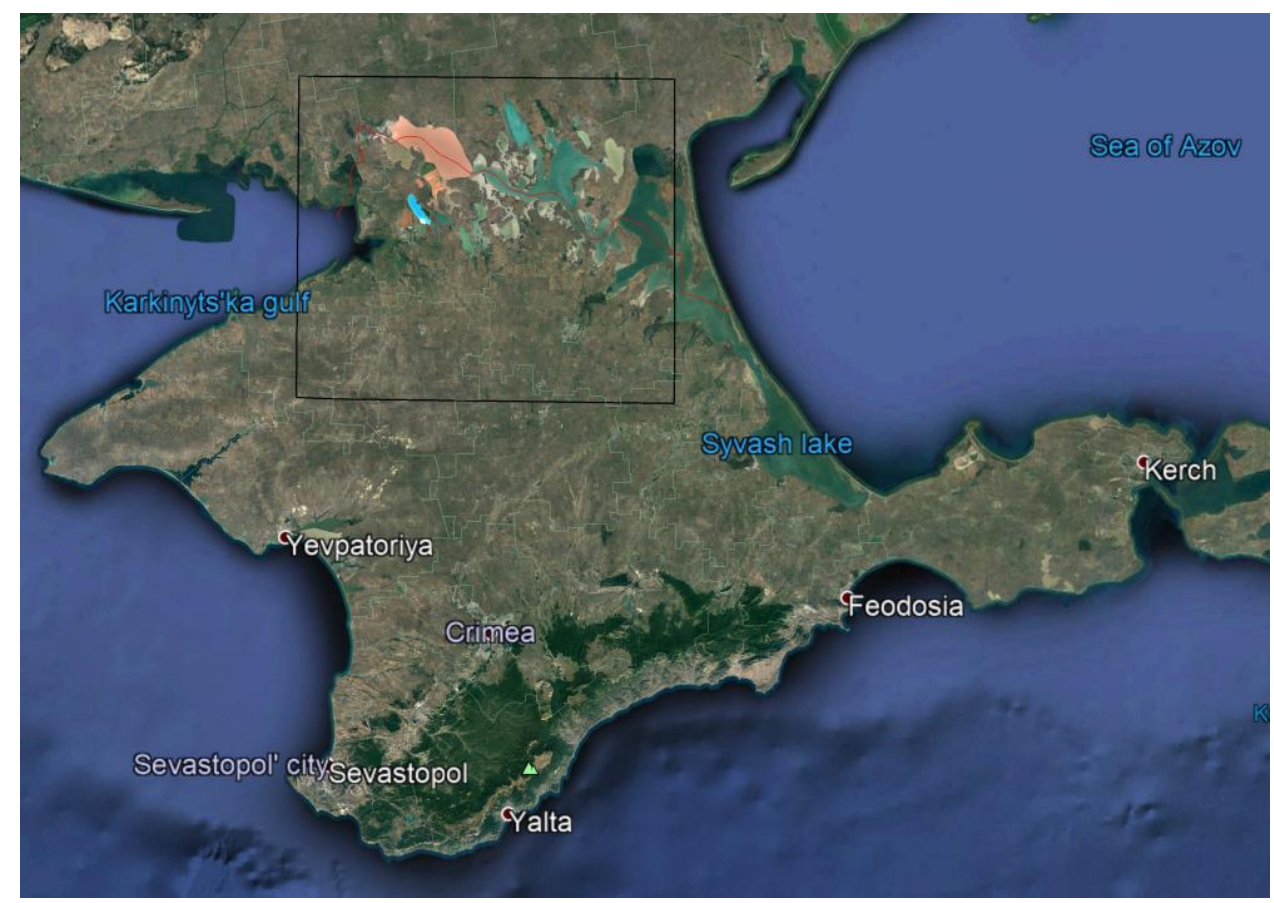

Fig.1. Study area (delineated with black line) 
The area is mainly used as agricultural land. Most of the arable land before 2014 was irrigated. After 2014, part of the arable land was abandoned or used for crop cultivation without irrigation. The analysis of changes in soil salinity was based on the comparison of Landsat 8 OLI satellite data obtained in 2013 and 2019. The Landsat 8 OLI sensor started operating in 2013 and allows imaging with a spatial resolution of 15 to 30 meters in 9 channels of visible, near and mid-infrared bands with a frequency of once in 16 days (https://www.usgs.gov/core-science-systems/nli/landsat/landsat-8?qtscience support page related_con=0\#qt-science_support_page related_con ).

Two satellite scenes obtained in September 2013 and 2019 were selected for the analysis. This period was chosen because active vegetation at this time of the year has already stopped and many cultivated crops are harvested and soils are plowed. Thus, the number of fields with open soil surface reaches its maximum at this time.

The data of 4 channels of visible and near-infrared bands were analyzed:

- Band 1 Visible $(0.43-0.45 \mu \mathrm{m}) 30 \mathrm{~m}$

- Band 2 Visible $(0.450-0.51 \mu \mathrm{m}) 30 \mathrm{~m}$

- Band 3 Visible $(0.53-0.59 \mu \mathrm{m}) 30 \mathrm{~m}$

- Band 5 Near-Infrared $(0.85-0.88 \mu \mathrm{m}) 30 \mathrm{~m}$.

The sequence of analysis is shown in Figure 2.

After atmospheric correction of initial data, NDVI maps were calculated for each of the scenes based on commonly used approaches [10]. Using these maps, the threshold index values for the masking of open soil surface were expertly determined. Based on these values, all pixels with vegetation and water were masked (excluded from further analysis).

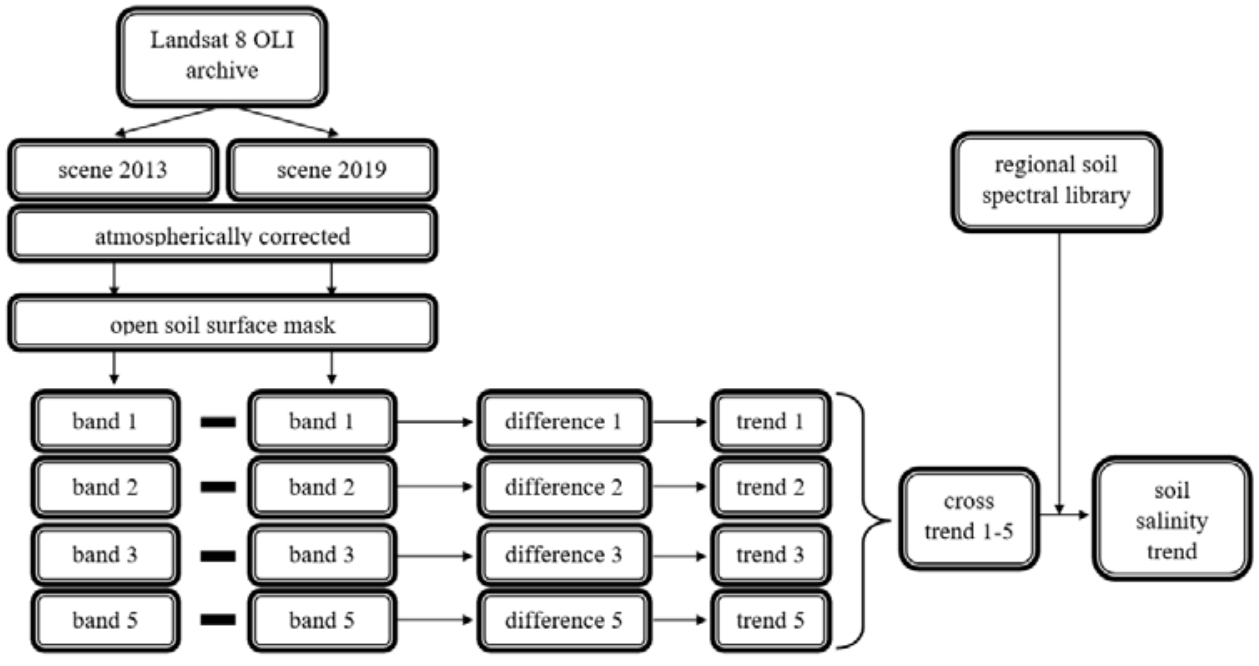

Fig.2. Flowchart of the research

Then, the images of the open soil surface were channel-by-channel subtracted from each other. That is, the difference in the spectral brightness of the images of each channel of 2019 and 2013 was calculated. After that, each image-difference was divided into the following classes: 1) no change in pixel brightness, 2) strong decrease in brightness, 3) weak decrease in brightness, 4) weak increase in brightness, 5) strong increase in brightness. The class limits were determined by analyzing the image-difference histogram for each channel. Brightness was considered to be unchanged if the values for 2019 and 2013 differed from each other by less than 10\%; a weak decrease and a weak increase were determined when the difference in brightness value was 10 to $25 \%$. A difference of more than $25 \%$ was considered a strong change. 
After such kind of classification of image-differences, the change class maps for each channel were intersected sequentially with each other. The result was an intersection map, in which each class shows how the spectral brightness of the pixels for all bands changed simultaneously.

Next, an expert interpretation of the intersection map was performed in terms of changes in soil salinity status.

The library of spectral reflectance of soils in the study region (unpublished data from the Soil Data Center at the V.V. Dokuchaev Soil Science Institute) was used as the basis for developing the decisive rule. This library contains data on the spectral reflectance of soil samples in the 350-1050 nm range obtained using a HandHeld-2 spectroradiometer (ASD, USA). Based on the analysis of these data, it was found that increasing the salt content in the soil sample of the study region leads to a strong increase in reflectance in the blue spectral region, a slight increase in the green spectral region, and a complete absence of growth in the red and infrared spectral regions. As a result, the following decisive rule for assessing changes in soil salinity was adopted (Table 1).

Table 1. Decision rules.

\begin{tabular}{|c|c|c|c|c|}
\hline soil salinity changes & Band 1 & Band 2 & Band 3 & Band 5 \\
\hline strong increase & ++ & + & + & $=$ \\
\hline slight increase & + & + & $=$ & $=$ \\
\hline no changes & $=$ & $=$ & $=$ & $=$ \\
\hline slight decrease & - & - & $=$ & $=$ \\
\hline strong decrease & -- & - & - & $=$ \\
\hline
\end{tabular}

= no changes in reflectance; - slight decrease in reflectance; -- strong decrease in reflectance;

+ slight increase in reflectance; ++ strong increase in reflectance

All other variants of soil reflection change were considered to be unrelated to soil salinity change.

Using this decisive rule, the intersection map was recoded into a map of soil salinity change of the study region.

All work with satellite images was performed using the GIS software package ILWIS v.3.3 (https://www.itc.nl/ilwis/download/ilwis33/).

\section{Results and Discussion}

The resulting map of soil salinity changes in the region between 2013 and 2019 is shown in Figure 3. According to the data obtained, soil salinity status in the study area did not change between 2013 and 2019 for 82 percent of all pixels analyzed. About $9.6 \%$ of them were classified as "strongly decreasing" salinity and $0.6 \%$ percent were classified as "slight decrease" Most of these pixels are located in areas of cropland that were continuously irrigated from 2013 to 2019 . That is, the constant flushing of the soil profile with irrigated water contributed to the fact that some of the soils that were saline from the surface in 2013 were no longer saline in the surface soil horizon in 2019.

About $2.4 \%$ of the pixels were assigned to the "slight increase" class and $5.3 \%$ to the "strong increase" class of soil salinity. As follows from the figure, most of the pixels with strong increase of salinity are located in the coastal parts of estuaries and lakes. That is, there is a decrease in their level, as a result of which the soils of the former coastal zones dry up, which leads to the appearance of additional areas with highly saline soils in the soil cover. Some pixels with increasing soil salinity are also confined to lacustrine and near- 
coastal zones, but there are also those located away from limans and lakes. Pixels in increasing salinity are not confined to the North Crimean channel. This is most likely due to the fact that the main massif of irrigated fields is also located not near the canal, but at a sufficient distance from it.

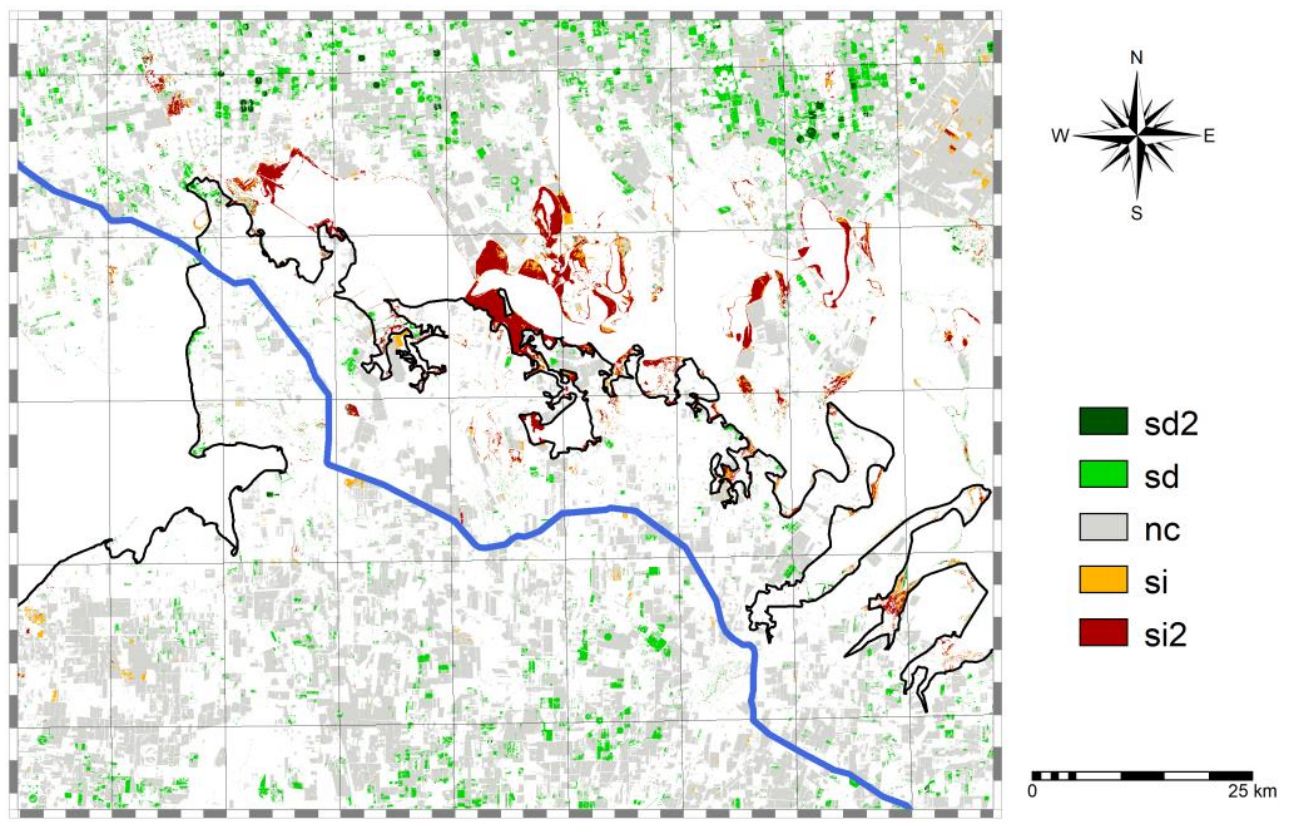

Fig.3. Changes in the status of soil salinity in the study area (sd2 - strong decrease, sd - slight decrease, nc - no change, si - slight increase, si 2 - strong increase, black line - border of the Republic of Crimea, blue line - North Crimean Channel)

Thus, there are multidirectional processes of soil salinity changes in the study area. Part of the soils is desalinized due to continuous irrigation, but at the same time, the proportion of saline soils increases by a comparable area (about 10\%) in other regions. Judging by the results, it is more likely that the main reason for the increase in the share of saline soils is not the cessation of water supply to the North-Crimean Canal, but the observed climate changes towards greater aridization and changes in level and salinity of Azov sea [11]. Those changes, which are noted by some researchers on the growth of soil salinity in the region $[8,12]$, so far have a local character and do not lead to increased salinization of the surface soil horizons.

It is necessary to take into account, of course, that the used approach has its limitations. First, based on this approach, it is impossible to analyze the entire territory, or only all the arable soils, since most of them at the time of the survey in any season are covered by vegetation. Thus, in our case, the surface of soils appeared to be open both in 2013 and in 2019 only on one third of the territory under consideration. This means that the results obtained characterize changes in only one-third of the soils. Second, these approaches analyze the presence of salts only in the surface soil horizon. And the change in salinity can manifest itself not only from the top, but also from the bottom of the soil profile. Therefore, the obtained results can be considered only as a solution of the set problem in the first approximation. 


\section{Conclusion}

Comparison of the satellite data of 2013 and 2019 showed that in the area of the NorthCrimean Canal there is both a slight expansion of the areas of saline soils and their reduction. The expansion of areas is observed mainly in the coastal zones of lakes and estuaries, and the reduction of areas in the fields, irrigation of which in the analyzed period did not stop. Both expansion and reduction of areas with saline soils did not exceed $10 \%$ of the study area. There is no evidence that the expansion of areas of saline soils during the analyzed period was due to the cessation of water supply to the North-Crimean canal.

The investigations were supported by Russian Science Foundation project No. 20-67-46017.

\section{References}

1. R. Vargas, E.I. Pankova, S.A. Balyuk, P.V. Krasilnikov and G.M. Khasankhanova, Handbook for saline soil management. (FAO. 2018)

2. FAO. Mapping of salt-affected soils - Technical specifications and country guidelines. (2020)

3. International Commission on Irrigation and Drainage Report (2012)

4. L. Shishov, E. Pankova (eds.), Salinized Soils of Russia (Academkniga, Moscow, 2006)

5. V. Korsak, R. Prokopets, O. Kurmangalieva, V. Afonin, Agrarian Sci. Ray, 8, 19-24 (2016)

6. A.F. Novikova, Eurasian Soil Science, 41(5), 529-541 (2008)

7. N. Stasiuk, Monitoring of Temporary Changes and Degradation of the Soil Cover with the Use of Remote Materials (MAKSpress, Moscow, 2016)

8. N. Khitrov, L. Rogovneva, V. Pashtetskiy, Dokuchaev Soil Bulletin, 102, 70-102 (2020)

9. N. Dragan, Soils of Crymea (SSU, Simferopol, 1983)

10. J. Rouse, R. Haas, J. Scheel, D. Deering, Proceedings, 3rd Earth Resource Technology Satellite (ERTS) Symposium, 1, 48-62 (1974)

11. A. Mizyuk, G. Korotaev, A. Grigoriev, O. Puzina, P. Lishaev, Physical Oceanography, 26(5), 438 (2019)

12. N. Khitrov, L. Rogovneva, Eurasian Soil Science, 54(1), 135-149 (2021) DOI: $10.31857 / \mathrm{S} 0032180 \mathrm{X} 21010044$ 